\title{
Exploring the similarities and differences between medical assessments of competence and criminal responsibility
}

\author{
Gerben Meynen
}

Published online: 11 June 2009

(C) The Author(s) 2009. This article is published with open access at Springerlink.com

\begin{abstract}
The medical assessments of criminal responsibility and competence to consent to treatment are performed, developed and debated in distinct domains. In this paper I try to connect these domains by exploring the similarities and differences between both assessments. In my view, in both assessments a decision-making process is evaluated in relation to the possible influence of a mental disorder on this process. I will argue that, in spite of the relevance of the differences, both practices could benefit from the recognition of this similarity. For cooperative research could be developed directed at elucidating exactly how various mental disturbances can affect decision-making processes.
\end{abstract}

Keywords Decision-making - Competence .

Criminal responsibility · Forensic psychiatry · Psychiatry · Law · Free will

\section{Introduction}

Assessments of criminal responsibility and assessments of competence to consent to treatment are important medical practices. In general they are performed, developed and debated in distinct domains. The assessment of criminal responsibility ${ }^{1}$ is a task usually performed by specifically trained forensic psychiatrists within a legal context (Gutheil 2005; Simon 2005). The evaluation of competence, on the other hand, is the common medical practice of

\section{G. Meynen ( $\square)$}

VU University Amsterdam, Faculty of Philosophy, EMGO

Institute VU Medical Center, De Boelelaan 1105, 1081HV

Amsterdam, Netherlands

e-mail: g.meynen@ph.vu.nl assessing a patient's ability to consent to treatment, usually performed in a medical setting (Appelbaum 2007). ${ }^{2}$ This paper intends to bring these two practices and the discussions surrounding them together by exploring similarities and differences between these assessments. Meanwhile, the main goal of the paper is to identify relevant similarities that could guide further research.

In my view, a similarity of both assessments (of adults) is that a decision-making process is evaluated in relation to the possible presence and influence of a mental disturbance. In general, assessing a decision-making process may, of course, also take place without any connection to mental disorder. For instance, one might want to assess a decisionmaking process in a company (see Hodgkinson and Starbuck 2008). This kind of decision-making, however, is not the topic of this paper. The paper focuses on the assessment of decision-making processes in the medical domain with respect to treatment options or legally relevant behavior. Recognizing a link between both assessments in principle opens the possibility of cooperation and a fruitful exchange between the two areas of expertise, at the level of training,

\footnotetext{
${ }^{1}$ In this paper I use the term "criminal responsibility" (see also Eastman and Campbell 2006). An alternative term could be 'insanity' (or 'legal accountability'). Within the context of forensic assessment they are often used synonymously (see, e.g. Gutheil 2005, p. 345). Meanwhile, there is some controversy whether forensic practitioners should in fact state something about the defendant being (not) responsible (see Sect. 4 on conceptual unclarity in forensic assessment). In this paper I do not intend to take an explicit position on the controversy. I use the term 'criminal responsibility' because it is usually connected to the relevant forensic assessment.

2 I will not make a distinction between the terms 'competence' and (decision-making) 'capacity'. Cf. Appelbaum (2007, p. 1834): “The terms "competence" and "capacity" are used interchangeably in this article, since the oft-cited distinctions between them-competence is said to refer to legal judgments, and capacity to clinical ones-are not consistently reflected in either legal or medical usage."
} 
developing guidelines and research. At the same time, significant differences between the two practices exist, which are relevant to further research as well.

The structure of the paper is as follows. In Sect. 2 I will briefly introduce the concept of decision-making and the different components that have been distinguished in the process of decision-making. In Sects. 3 and 4 I will discuss the assessments of competence and criminal responsibility in terms of an evaluation of decision-making processes in relation to a mental disturbance. I will also discuss to what extent both assessments face conceptual and operational difficulties. In Sect. 5 I will articulate and explore some important differences between both types of assessment. Yet, within the framework of this paper, I will not be able to provide an exhaustive account of the differences. In Sect. 6 I will, tentatively, discuss implications and opportunities for further research on both assessments.

\section{Decision-making}

It is hard to exactly define decision-making (see, e.g., Bermudez 2009). One way to conceive of decisions is presented by Clarke (2007, p. 391): "When one makes a decision, one actively forms an intention to perform an action of a certain type." In this conception of decision, as in many philosophical accounts of decision-making, the concept of intention is central (see also Kalenscher and Tobler 2008). Another way to approach decision-making is by recognizing three different phases in the process (Kalis et al. 2008). The first phase is the generation of options, the second phase is the selection of options, and the third phase is the initiation of action. Options are understood here as consisting of both these elements: being a possible action, and having an affective value for the person concerned. Kalis et al. (2008) emphasize that the first phase, the generation of options, has been neglected in research on decision-making. Interestingly, they link specific mental disorders to problems that may occur in each of the phases of decision-making. An example of a problem in one of the phases is apathy. Perhaps this condition could be understood as a state entailing hypogeneration of options. In contrast, in a manic episode, hypergeneration of options might occur (Kalis et al. 2008). A problem in the second phase, option selection, could occur in conditions like impulsivity. In such a condition there is a lack of control, which hampers the selection of the (right) option. Impulsivity could also affect the third stage of decision-making: too early initiation of action.

Whereas the assessment of competence is usually linked to decision making-decision-making capacity being almost synonymous with competence (Charland 2008) the assessment of criminal responsibility is not usually understood in these terms. In this paper, however, I will, tentatively, understand both assessments from the perspective of decision-making (see Sects. 3 and 4). In this respect, the approach chosen by Kalis et al. (2008) is interesting because of the explicit link between mental disorders and problems in specific phases of decisionmaking. In Sects. 3, 4 and 6, I will briefly return to their proposal.

\section{Competence}

The assessment of competence

As a general principle, doctors are required by law and ethics to obtain the informed consent of their patients before starting treatment. ${ }^{3}$ Valid informed consent is only obtainable in case the appropriate information has been disclosed to a competent patient who is permitted to make a voluntary choice (Paterick et al. 2008). Generally, four abilities are considered requirements for decision-making capacity. Firstly, the ability to express a choice, secondly, the ability to understand the relevant information, thirdly, the ability to appreciate one's situation and the consequences of the options, and finally, the ability to reason about treatment choices (Simon 2005; Appelbaum 2007). The fact that competence is crucial in any consent to treatment implies that physicians must always be aware of the possibility that patients may in fact have impaired decision-making capacity. It also implies that physicians must be skilled at evaluating that possibility. The clinical importance of this skill is underlined by the fact that patients lacking this capacity are commonly found in medical and surgical inpatient units (Appelbaum 2007). Recently, Owen et al. (2008) found that lack of mental capacity to make decisions about treatment is also common (60\%) in people admitted to a psychiatric hospital.

If a patient lacks the competence to make a decision about treatment, this prompts action on the part of the doctor, namely to seek a substitute decision-maker (see also Nicholson et al. 2008; Simon 2005). ${ }^{4}$ Clearly, by assigning a substitute decision maker, no 'ideal' situation is created; although valuable for the medical process, the substitute decision-maker is no more than, indeed, a substitute for a real autonomous decision by the patient him or herself (see also Buchanan and Brock 2004).

\footnotetext{
${ }^{3}$ Certain exceptions (see Simon 2005) exist to the requirement of informed consent, the most common being a case of emergency while the patient is unable to consent to treatment.

${ }^{4}$ See Jonsen et al. (2006, especially pp. 90-91, 114) for substitute decision-making in relation to "best interest". See Kopelman (2007) on different understandings of "best interest" in relation to incompetence.
} 
Mental disorder and competence

It is important to note the relationship between impairment of competence and mental disturbance or disorder. Appelbaum (2007, p. 1835) says: "Any diagnosis or treatment that compromises mentation may be associated with incompetence." I will not go into detail about how, exactly, we should understand mental disorder. There is much debate on how to conceive of mental disorders conceptually (see, e.g., Bolton 2008; Thornton 2007). In my perception, given the medical context of both assessments, the term mental disorder could be used. I assume however that not all cases of incompetence can be classified in terms of mental disorders like psychosis, or major depression. But mental disturbances that lead to incompetence will generally be found in, e.g., the Diagnostic and Statistical Manual for Mental Disorders (DSM-IV, American Psychiatric Association 1994). ${ }^{5}$ Others might prefer the term 'mental dysfunction' to 'mental disorder'. In my view, however, while the term dysfunction might be more appropriate in (neuro)cognitive research, within the medical domain of both assessments, the term disorder is more appropriate.

The central point is that conditions compromising mentation (Appelbaum 2007) are the kind of conditions potentially associated with incompetence. According to Nicholson et al. (2008), explaining the Mental Capacity Act (United Kingdom 2005), lack of competence requires impairment of functioning of mind or brain (for example cognitive impairment, mental disorder, delirium, or intoxication). I also take him to mean that there has to be some sort of mental disorder or disturbance, for if an intoxication does not lead to any mental disturbance, there is, in my view, no way it will influence competence. Put otherwise, in general, a person without any mental disturbance is considered competent to make a decision on treatment options, as long as the relevant information has been provided (and there are no external factors such as a threat).

The relation with mental disorder could also explain why psychiatric consultation may be helpful in "particularly complex cases" of assessments of competence (Appelbaum 2008, p. 1837). As an analogy, many physicians can treat urinary tract infections, but in 'particularly complex cases' it is the urologist who may be helpful. This is not because urologists just happen to be skilled in 'complicated' urinary tract infections, but because the urinary tract and its disorders are the remit of the urological specialty. Similarly, there is an intricate relationship between psychiatry and impairment of decision making

\footnotetext{
5 As far as the DSM-IV is concerned some relevant disorders could perhaps be classified as "293.9 Mental Disorder NOS Due to...[Indicate the General Medical Condition]".
}

capacity: such incapacity arises in cases of mental disorder, which in medical practice is the remit of the psychiatric specialty.

Meanwhile, it is of equal importance to emphasize that people may be perfectly competent with respect to decisions about their treatment while suffering from a (severe) mental disorder. As Appelbaum (2007, p. 1835) puts it, "no diagnosis in which consciousness is retained is invariably predictive of incapacity." For instance, studies have found that more than half—but not all—of the patients with mildto-moderate dementia may have impaired decision-making capacity (Appelbaum 2007). And this, of course, is what calls for special expertise on the part of physicians in general and the consultant psychiatrist in particular. For it is not (just) about establishing the presence of a mental disorder or disturbance, but about evaluating a decision process in relation to the (possible) presence and influence of a mental disorder.

\section{Clarity of the assessment}

Given the central role of the assessment of competence in all medical treatment, it is disturbing that the performance of capacity assessments is "often suboptimal" (Appelbaum 2007). There are, at least, two major problems. First, physicians are frequently unaware of a patient's incapacity for decision-making. Second, when incapacity is suspected, doctors may not know which standard to apply. Hurst et al. (2007) found that doctors report uncertain or impaired decision-making capacity as a very frequently encountered ethical difficulty in clinical practice. In fact, there is no gold standard that tells a physician exactly what competence is. According to Simon (2005, p. 3982), "no firmly established criteria exist for determining a patient's competence." Yet, various instruments, like the MacArthur scale (Grisso et al. 1997), have turned out to be of practical help in the evaluation process of competence (see Jeste et al. 2007; Owen et al. 2008).

In fact, there is not only a lack of practical guidelines, but there remains conceptual unclarity how to basically understand decision-making capacity. This is illustrated by a comment on Appelbaum (2007) by Spike (2008). Appelbaum mentioned that the decision being 'reasonable' is a criterion for competence. Spike (2008, p. 644), however, says that decision-making capacity "has more to do with acting characteristically than with acting reasonably." Spike's comment makes at least some sense to me: it seems to be important that it is the patient's own choice, consistent with who he or she is. And one way of putting this might be to say he or she is choosing 'characteristically'. However, the problem is that Appelbaum's (2008, p. 644) reply also makes sense: "Although Spike would favor application of a consistency standard rather than reasoning, 
this is not generally accepted-for good reason. Consistency with past behavior is a difficult determination, especially for unprecedented decisions (e.g., amputation); moreover, a consistency standard risks denying patients the right to choose differently today than they have in the past." So, there remain pressing issues not only with respect to practical guidelines, but also concerning the conceptual elucidation of what competence is actually about (see also Welie 2008).

In this section, I have proposed that assessments of competence can, in general, be conceived of as assessments of decision-making processes in relation to the possible presence and influence of a mental disorder. Considering the three phases of decision-making (Kalis et al. 2008), the emphasis in assessments of competence, in general, will be on the capacity of option selection. The generation of options seems to be of less importance, since within the medical setting the options have often already been selected by the doctor or other healthcare worker. The actual initiation of action, in my view, will also be of less importance.

\section{Forensic assessment of criminal responsibility}

The nature of the assessment

According to Gutheil (2005, p. 357), the "core of the insanity issue" in forensic psychiatry is the "application of legal (usually statutory) criteria to a mental condition in a defendant at the time of the act in question to determine whether he or she should be held responsible". A common way to understand the forensic role, using other terms, is by referring to the fact that the judicial system requires two elements to be able to hold a person accountable for a criminal offence: the criminal act as such (actus reus) and intent (mens rea, latin for "guilty mind"). (see, e.g., Zemishlany and Melamed 2006; Morse 2007). As Zemishlany and Melamed (2006) put it: "A person who, as a result of severe mental disease or defect, is not able to appreciate the nature and quality of his or her acts is not held responsible for committing them." This judicial approach is also linked to a famous case from the British courts (1843), where rules were developed to guide an insanity defense, known as "the M'Naghten rules" (Simon 2005).

The rules can be phrased (Elliott 1996, p. 11) as, "at the time of committing the act, the party accused was laboring under such a defect of reason, from the disease of the mind, as not to know the nature and quality of the act he was doing; or if he did know it, that he did not know what he was doing was wrong." M'Naghten is, as Elliott (1996, p. 10) says, "by far the most influential, the most widely quoted, and the most roundly criticized test of legal insanity". An important point of criticism has been that it focuses on 'reason' and cognitive capability too much. For mood and affect are also important factors (Elliott 1996, pp. 11-12). ${ }^{6}$ Another point of criticism is that the nature of the knowledge is not clear. For instance: is it knowledge about the fact that the law says that the act is wrong, or is it about moral wrongness? Meanwhile, it has been the standard for the defense of insanity in most Anglo-American jurisdictions. $^{7}$

Problems concerning the assessment

For various reasons the forensic psychiatrist's task is considered complicated (Gutheil 2005). It is generally recognized that the fact that the psychiatrist is operating on interdisciplinary territory is closely related to the difficulties encountered. According to Van Marle and Van der Kroft $(2007$, p. 511), "the difficulty in understanding the essence of forensic psychiatry is that it is a medical profession within the multidisciplinary field of criminal justice, social control and empirical sciences within a social context."

In addition, what makes the forensic psychiatrist's task hard is that the (conceptual) framework within which he or she works is not completely clear (see Gutheil 2005; Simon 2005). A significant area of unclarity concerns the "ultimate question'. Should forensic psychiatrists express their view whether the defendant is actually responsible (or not responsible) for the act? Some have suggested that psychiatrists should not make the inference that the person is responsible, because it is a 'fact' and psychiatrists should not be 'fact-finders' (Gutheil 2005). Psychiatrists, then, should say no more than: "The defendant lacks substantial capacity to appreciate the wrongfulness of the act", without expressing an explicit view on the 'ultimate issue' of moral responsibility. Others have argued that "all forensic evidence is opinion anyway" (Gutheil 2005, p. 355), and that juries are explicitly instructed to deal with forensic evidence as such.

Another thorny issue is whether it is the psychiatrist's task to determine whether the committed act was performed 'freely'. Some consider freedom inescapable to the forensic psychiatrist's assessment (Luthe and Rösler 2004; Meynen 2009). Others argue that the concept of free will should be avoided by forensic practitioners, because the law itself does not require 'free will' in order to be able to hold a person responsible (Morse 2007). According to Morse, therefore, the concept of freedom or

\footnotetext{
${ }^{6}$ It has also been argued that the role of emotions in competence has not received due attention (Charland 2008).

${ }^{7}$ See also Eastman and Campbell (2006) on neuroscience and legal determination of criminal responsibility.
} 
free will is irrelevant to the forensic task, and using the term would only spawn confusion. More precisely, there is concern that forensic psychiatrists may get entangled in metaphysical issues of free will and determinism (Stone 2008). Felthous (2008) has recently proposed dropping the word 'free' in relation to forensic work, and to focus on the concept of will (and not on free will).

On a more practical level, there is at present no instrument or (gold) standard to help the forensic practitioner in his or her task (Henderson 2005; Simon 2005). Henderson (2005) even appears to doubt its feasibility.

\section{Decision-making and mental disorder}

In my view, the assessment of criminal responsibility or 'insanity' could also be understood in terms of the influence of a mental disorder on a specific decision-making process (the process that led to the act). As Buchanan (2000, p. 80) says: "If psychiatric conditions are to be grounds for exculpation, they must impair the sufferer's ability to choose" (see also Adshead et al. 2008). ${ }^{8}$ I would propose to understand choosing in terms of decisionmaking. There may be numerous reasons why a person cannot be held accountable for an act, but it is the forensic psychiatrist's task as a medical specialist to relate the decision-process that led up to the act to the possible influence of a mental disorder-why would the courts otherwise ask psychiatrists to make these assessments?

Surely, in some cases no decision may have been made before the act. But if a forensic psychiatrist concludes that no decision took place before the act, this usually will also be valuable information to the court. Simon (2005), for instance, mentions several exculpatory and mitigating conditions in forensic psychiatry, like automatisms. A (classic) exculpatory example is sleepwalking. In such states actions occur "without will, purpose, or reasoned intention." (Simon 2005, p. 3985) I would argue that in these conditions of parasomnia (states of lowered consciousness, see also Elliott 1996, p. 12) there is no (real) decision-making process leading to the act. In such cases it may be very relevant to a jury that the forensic practitioner reports that the act was committed without a (real) decision-making process.

I propose to view the forensic task basically as consisting of three components: first, assessing whether a mental disturbance was present at the time of the act, second, assessing the decision-making process that led up to the act, and, third, assessing whether the decision-

\footnotetext{
${ }^{8}$ Speaking about the forensic assessment in terms of assessing the 'decision-making' of the defendant, as I do, is not new (see e.g. Buchanan 2008 on Felthous, and Beauregard 2007).
}

making process was decisively influenced by the mental disorder (see also Morse 2007). In fact, these three elements are not completely distinct activities; there is a practical intertwinement. For assessing the decision-making process can provide information about the presence of a mental disorder. If a person tells the forensic practitioner that he hit his neighbor because he thought the neighbor was spying on him day and night and transferring information to the CIA, this may give information about the presence of a mental disorder, and also about its influence on the legally relevant act.

Distinguishing the three phases of decision-making (Kalis et al. 2008, see Sect. 2) can also be relevant to criminal responsibility. In my view, to a greater degree than in assessments of competence, the generation of options is relevant. For instance, did a delusion decisively influence the options perceived/generated by the defendant? In the case of making a decision about treatment options, these options are given (by the doctor), while in 'real life' situations there are usually no fixed options. The other two phases are also relevant: how did a person select an option (perhaps delusions or cognitive impairments influenced the selection), and were there problems initiating (or inhibiting) an action (this might relate to impulse control problems)?

Up till now I have tried to bring forward a specific similarity between the medical assessments of competence and criminal responsibility. In my view, they have in common that they evaluate a decision-making process in relation to the possible influence of a mental disorder. Both assessments are, in addition, related to normative concepts: either the competence to choose between treatment options, or the responsibility for one's actions. Still, the practices of assessing competence and criminal responsibility differ in many relevant respects. In the next section I will address what I consider important differences-although the list is not meant to be exhaustive.

\section{On the differences between both assessments}

The differences between the forensic assessment of criminal responsibility and the assessment of competence to consent to treatment are many. In general, of course, they are related to the fact that forensic assessments are performed in a juridical environment and related to a legally relevant act, while the assessment of competence is performed in a medical environment related to choosing a treatment option. The differences also explain, to a certain extent, why both assessments are discussed and studied in separate domains. Although the differences are undeniable, I will also show how some of the differences could be bridged. 
Responsibility versus autonomy

The forensic psychiatrist's task is to assess whether the person who performed a legally relevant act can be held accountable, or responsible for this act (see above in Sect. 4 for hesitations about this view, Gutheil 2005). Meanwhile, the central concept behind decision-making capacity is considered to be autonomy (see, e.g., Dekkers 2001). For the significance of competence is linked to the fact that we value a person's autonomy (Welie and Welie 2001). We want, as Owen et al. (2008) say, "an individual's autonomous decisions relating to the acceptance and refusal of medical treatment [to] be respected." So, as it seems, we are confronted with the difference between the concepts of 'responsibility' (in assessments of criminal responsibility) and 'autonomy' (in assessments of competence).

Yet, although at first glance there seems to be a difference, it turns out that competence too could be understood in terms of responsibility. This is shown by Welie and Welie (2001, p. 129). They say that "it is generally believed that patients (...) carry final responsibility for their own health care (or at least the acceptance or refusal thereof). If a patient refuses much needed medical care, no one but the patient is responsible for that decision. Patients have a right to be left alone. But we can only hold persons responsible if they could have made a different decision, if they were free and able to reach a different decision. Competence is the patient's ability to make a choice about the various medical interventions offered to her by the caregiver, and to bear accountability for that choice." So, competence, apparently, can be understood in terms of responsibility and accountability. Therefore, although at first sight there may be a conceptual difference between responsibility (in forensic assessment) and autonomy (in assessment of competence), both can be expressed in terms of responsibility. In other words, the conceptual gap, as it appears, can be bridged.

\section{Act versus choice}

Forensic practice pertains to a criminal act, while assessing competence pertains to a choice about medical treatment. Again, at first glance, this might seem a clear difference. But, in my view, there are three things we should consider. Firstly, one of the criteria for competence to consent to treatment is to be able to communicate or to express a choice. This is an act. Secondly, making a decision can also be considered an act. As Buchanan and Brock (2004, p. 18) put it: "Competence is competence for some task, competence to do something. The concern here is with competence to perform the task of making a decision." This is in line with Beauchamp and Childress (2001, p. 70) who state: "A single core meaning of the word competence applies in all contexts. That meaning is "the ability to perform a task". Third, consider a case of perjury. In this case the criminal act can be no more than the (false) answer "yes" or "no". Crimes do not always take a lot of 'action'. So, although there is a difference between act and choice, this difference can also, to some extent, be bridged.

\section{Unlawful (act) versus legal (choice)}

In forensic work the central act of which the decisionmaking process has to be assessed, is unlawful. In the case of assessing competence, the treatment options are, in principle, all legal and admissible. The doctor is not allowed to propose illegal medical options. Meanwhile, I would argue, patients have to be able to appreciate the situation, and value the consequences, which can very well imply an ethical dimension of these consequences, for instance, the consequences for loved ones. In general, when making (major) decisions in life (like some decisions about medical treatment), it is important to have an understanding of the ethical dimension of the options and also their 'lawfulness'. Still, forensic assessment, in Simon's view (2005), is explicitly about assessing whether there is "a lack of knowledge of the nature or wrongfulness of the act". So (understanding) the unlawful nature of the act could, then, be considered specific for forensic work. ${ }^{9}$

\section{Initiated by a legal authority versus treating physician}

This difference is closely related to the kind of act/choice of which the decision-making process is central to the examination. In forensic assessment it is a legally relevant act, while in assessment of competence it is (in the standard case) a choice about medical treatment. From this difference of context and domain do stem a lot of pitfalls in forensic work (see Gutheil 2005). For instance, confidentiality, a core characteristic of the usual doctor patientrelationship, does not apply in the same way in the forensic setting. This implies, on the part of the forensic practitioner, the obligation to make sure that the defendant is fully aware of the actual kind of relationship there is. Yet, this difference does not undermine the view that the assessment itself is about a decision-making process in relation to mental disorder.

\footnotetext{
${ }^{9}$ In principle, of course, during the legal procedures it may turn out that an act was not unlawful after all. In addition, much more can be said about the "wrongfulness" of the act. I do think, however, that there is some prima facie difference in this respect between forensic assessment and evaluation of competence, and it is just common sense that it has to be addressed in (forensic) training.
} 
'Main outcome': punishment versus medical procedure

The fact that the outcome of forensic assessment may (indirectly) result in legal punishment is a clear difference compared to the assessment of competence, where it is about a medical procedure. (The possibility of being misled by the examinee in forensic work may primarily have to do with this feature of forensic work.) But the consequences, in my view, do not constitute a fundamental difference. For both assessments are not basically about imposing punishment or providing treatment, but about evaluating the decision-making process that led up to the act/choice.

\section{Retrospective versus current/prospective}

Forensic assessment is an evaluation in retrospect-an important complication of this kind of assessment. The act has been committed and the assessment is about the decision-process that led up to the act. In contrast, in the assessment of competence the choice is (usually) currently being made, or it will be made soon. This means that in forensic assessments specific skills are required to reliably assess a decision-making process in retrospect.

As an additional difference it can be mentioned that the two practices, in general, encounter different mental disorders. In forensic assessment 'insanity' is usually associated with psychotic phenomena (Rogers and Sewell 1999; Elliott 1996, p. 12). Questions about competence, on the other hand, are often related to cognitive impairment due to dementia and other organic syndromes (see Raymont et al. 2004, also Buchanan and Brock 2004, p. 1, Candilis et al. 2008).

So, there are important differences. Considering these mainly shows the complexity of the forensic task: operating as a medical expert in legal territory, making an assessment in retrospect about a non-medical (even unlawful) act. These complexities certainly have their bearings on research aimed at elucidating the forensic task of assessing criminal responsibility. Yet, and this is an important point, the differences between both assessments do not falsify relevant similarities as identified previously. Within the framework of this paper, I will not further address these differences or their consequences for further research. I will focus on the opportunities for both assessments if they are approached from their common ground.

\section{Implications and opportunities}

Although there are undeniable differences between both assessments, there is also significant common ground. Both are assessments of decision-making processes and the possible influence of mental disorder on these processes. Both, in addition, are 'decision-specific' (Buchanan and Brock 2004, p. 22): they refer to a specific (unlawful) act or (medical) choice. Finally, both assessments are considered to be linked to related normative concepts like autonomy and responsibility.

The first practical implication of their similarity is that research on criminal responsibility could, in principle, benefit from the approach chosen by research on competence. The progress that has been made in finding at least some consensus with respect to a set of criteria (Appelbaum 2007) and the development of a scale (MacArthur), ${ }^{10}$ and also practical research (like Owen et al. 2008), could be a useful example for research on criminal responsibility. Relevant aspects of this approach can be subsumed, in my view, under the term 'empirical ethics'.

It may be hard to precisely define empirical ethics. In general, empirical ethics strives, alongside conceptual analysis, to obtain relevant empirical data. It can do so via different methods, for example: observations, interviews and questionnaires (Eastman and Starling 2006; Widdershoven et al. 2008). Empirical ethics has proven to be a possible approach to many normative health issues, like questions about end-of life decisions, and also competence and informed consent (Widdershoven et al. 2008; Eastman and Starling 2006). Widdershoven et al. (2008, p. 19) understand empirical ethics as follows: "We suggest that for an enterprise to be called empirical medical ethics it must include ethical (normative) analysis. And to be empirical it must involve the systematic collection of data." They emphasize the interaction between both processes, which they call an interactive cycle. Another important characteristic of empirical ethics is that it is familiar with the interface of medicine and law (Eastman and Starling 2006; Welie 2008). To be sure, the approach in research on competence has not eliminated all problems and it has not led to a general consensus (Welie 2008). Also, on a meta-ethical level, one could ask questions about exactly how empirical data and ethics can be integrated-integrating ' $i s$ ' and 'ought' issues (Van der Scheer and Widdershoven 2004). Yet, my proposal is not meant to eliminate all possible conceptual problems, but to suggest an approach to criminal responsibility that has led to some conceptual and practical elucidation with respect to competence.

In addition to empirical ethics, there is, in my view, another approach that might be helpful to both assessments. This is research on decision-making processes in relation to specific mental disorder. Recently cognitive

\footnotetext{
${ }^{10}$ Many scales have been developed. For an overview, see Vellinga et al. 2004.
} 
(neuro)scientists have become interested in linking disorders of decision-making to specific mental disorders (Bechara 2005; Kalis et al. 2008; Paulus 2007). An example is the study on dysregulation of decision-making in specific mental disorders by Cattapan-Ludewig et al. (2008). They found (using a two-choice prediction task) that decision-making behavior of first-episode schizophrenia patients was characterized by a high degree of dysregulation. Another example is the study by Sevy et al. (2007). They observed widespread impairments in several cognitive domains and emotion-based decision-making in schizophrenia (in relation to the use of cannabis). A slightly different design, but still linking a specific mental disorder to decision-making, was followed by Candilis et al. (2008). They studied decision-making capacity in schizophrenia and physically ill subjects. Importantly, they not only found impaired decision-making in schizophrenia, but also found that decision-making capacity was comparable to comparison subjects in a large part of the schizophrenia patients. This kind of research, specifically addressing decision-making in relation to circumscribed disorders, may also provide a way to proceed for research on both assessments. The subdivision as proposed by Kalis et al. (2008) (generation, selection, and initiation, see Sect. 2), could provide an initial framework to approach decision-making in psychopathology.

In fact, one of the main practical effects of conceiving of both medical tasks in the way proposed is that it opens the possibility of linking these empirical studies to concrete questions on competence and criminal responsibility. Such research could also help to optimize decision-making capacity in the relevant disorders.

With respect to research it is important that both medical practices are strongly embedded in legislation and regulations which may differ from country to country. In forensic work such differences include whether psychiatrists explicitly state whether the defendant is accountable or not (the 'ultimate question', see, e.g., Gutheil 2005). Yet, my proposal to conceive of the forensic task as evaluating the influence of a mental disorder on a specific decisionmaking process, does not rely on assuming that the forensic psychiatrist has to make a statement about criminal responsibility.

With regard to competence, differences between countries may involve the explicit relationship between competence and mental disorder or dysfunction. While the Mental Capacity Act 2005 (Nicholson et al. 2008) articulates such a relationship, other conceptions of competence may not express this connection (Vellinga 2006). Yet, even if one would disagree that, on a conceptual level, incompetence necessarily involves a 'mental disorder', on a practical level incompetence is related to (severe) mental disorders (see, e.g., Vellinga 2006).

\section{Conclusion}

Decisions may be the most important things we make. Assessing the process through which they come about may be one of the most complicated jobs there is. Society, medicine and the law are especially interested in the exact process that led up to a decision, when there are concerns about a person's autonomy and criminal responsibility. In such cases, doctors (especially psychiatrists) may be asked to act as experts in-as I tentatively propose to put it - assessing the decision-making process and the possible influence of a mental disorder on this process. This kind of assessment is taken very seriously, and it may have serious consequences. In spite of the differences between both evaluations, the similarities justify, in my view, a cooperative effort on conceptual and practical research on decision-making in relation to mental disorder. Apart from doing further (cooperative) research on these assessments, it may be wise to train doctors in assessing (crucial) decision-making processes in relation to the presence of mental disorder.

Acknowledgment This work is financially supported by NWOVENI research-Grant no. 275-20-016.

Open Access This article is distributed under the terms of the Creative Commons Attribution Noncommercial License which permits any noncommercial use, distribution, and reproduction in any medium, provided the original author(s) and source are credited.

\section{References}

Adshead, G., C. Brown, E. Skoe, J. Glover, and S. Nicholson. 2008. Studying moral reasoning in forensic psychiatric patients. In Empirical ethics in psychiatry, ed. G. Widdershoven, et al.. New York: Oxford University Pres.

American Psychiatric Association. 1994. Diagnostic and statistical manual of mental disorders, 4th ed. Washington, DC: American Psychiatric Association.

Appelbaum, P.S. 2007. Assessment of patients' competence to consent to treatment. New England Journal of Medicine 357: 1834-1840.

Appelbaum, P.S. 2008. Response on spike's comment: Patients' competence to consent to treatment. New England Journal of Medicine 358(6): 644.

Beauchamp, T.L., and J.F. Childress. 2001. Principles of biomedical ethics, 5th revised edn. New York: Oxford University Press.

Beauregard, E. 2007. An application of the rational choice approach to the offending process of sex offenders: A closer look at the decision-making. Sexual Abuse: A Journal of Research and Treatment 19(2): 115-133. doi:10.1177/107906320701900204.

Bechara, A. 2005. Decision-making, impulse control and loss of willpower to resist drugs: A neurocognitive perspective. Nature Neuroscience 8: 1458-1463.

Bermudez, J.L. 2009. Decision theory and rationality. Oxford: Oxford University Press.

Bolton, D. 2008. What is mental disorder. An essay in philosophy, science, and values. Oxford: Oxford University Press.

Buchanan, A. 2000. Psychiatric aspects of justification, excuse and mitigation. London: Jessica Kingsley. 
Buchanan, A.E., and D.W. Brock. 2004. Deciding for others. The ethics of surrogate decision-making. Cambridge: Cambridge University Press.

Buchanan, A. 2008. Commentary: Freedom and function. The Journal of the American Academy of Psychiatry and the Law 36: 25-26.

Candilis, P.J., K.E. Fletcher, C.M. Geppert, C.W. Lidz, and P.S. Appelbaum. 2008. A direct comparison of research decisionmaking capacity: Schizophrenia/schizoaffective, medically ill, and non-ill subjects. Schizophrenia Research 99(1-3): 350-358.

Cattapan-Ludewig, K., S. Ludewig, N. Messerli, F.X. Vollenweider, A. Seitz, J. Feldon, and M.P. Paulus. 2008. Decision-making dysregulation in first-episode schizophrenia. Journal of Nervous and Mental Disease 196(2): 157-160.

Charland, L. 2008. Decision-making capacity. Stanford Encyclopedia of Philosophy online. http://plato.stanford.edu/entries/decisioncapacity.

Clarke, R. 2007. Commanding intentions and prize-winning decisions. Philosophical Studies 133: 391-409.

Dekkers, W.J.M. 2001. Autonomy and dependence: Chronic physical illness and decision-making capacity. Medicine, Health Care and Philosophy 4: 185-192.

Eastman, N., and C. Campbell. 2006. Neuroscience and legal determination of criminal responsibility. Nature Reviews Neuroscience 7: $311-318$

Eastman, N., and B. Starling. 2006. Mental disorder ethics: Theory and empirical investigation. Journal of Medical Ethics 32: 94-99.

Elliott, C. 1996. The rules of insanity. Moral responsibility and the mentally ill offender. Albany: State University of New York.

Felthous, A.R. 2008. The will: From metaphysical freedom to normative functionalism. The Journal of the America Academy of Psychiatry and the Law 36: 16-24.

Grisso, T., P.S. Applebaum, and C. Hill-Fotouhi. 1997. TheMacCATT: A clinical tool to assess patients' capacities to make treatment decisions. Psychiatric Services 48: 1415-1419.

Gutheil, T.G. 2005. Ethics and forensic psychiatry. In Psychiatric ethics, ed. S. Bloch, P. Chodoff, and S.A. Green, 345-362. Oxford: Oxford University Press.

Henderson, S. 2005. The neglect of volition. British Journal of Psychiatry 186: 273-274.

Hodgkinson, G.P., and W.H. Starbuck (eds.). 2008. The Oxford handbook of organizational decision making. Oxford: Oxford University Press.

Hurst, S.A., A. Perrier, R. Pegoraro, S. Reiter-Theil, R. Forde, A.M. Slowther, E. Garrett-Mayer, and M. Danis. 2007. Ethical difficulties in clinical practice: Experiences of European doctors. Journal of Medical Ethics 33(1): 51-57.

Jeste, D.V., B.W. Palmer, P.S. Appelbaum, S. Golshan, D. Glorioso, L.B. Dunn, K. Kim, T. Meeks, and H.C.D. Kraemer. 2007. A new brief instrument for assessing decisional capacity for clinical research. Archives of General Psychiatry 64(8): 966-974.

Jonsen, A.R., M. Siegler, and W.J. Winslade. 2006. Clinical ethics: A practical approach to ethical decisions in clinical medicine, 6th ed. New York: McGraw-Hill.

Kalenscher, T., and P.N. Tobler. 2008. Interdisciplinary perspectives on decision making. Cognitive, Affective, and Behavioral Neuroscience 8(4): 345-347.

Kalis, A., A. Mojzisch, T.S. Schweizer, and S. Kaiser. 2008. Weakness of will, akrasia, and the neuropsychiatry of decision making: An interdisciplinary perspective. Cognitive, Affective, and Behavioral Neuroscience 8(4): 402-417.

Kopelman, L.M. 2007. The best interest standard for incompetent or incapacitated persons of all ages. Journal of Law, Medicine and Ethics 35(1): 187-196.

Luthe, R., and M. Rösler. 2004. Freedom of will, freedom of action and psychiatry: Concerning the relationship of empirical to intelligible character and so-called freedom of choice in the view of forensic psychiatry. In Philosophy and psychiatry, ed. T. Schramme, and J. Thome, 295-308. Berlin: De Gruyter.

Meynen, G. 2009. Should or should not forensic psychiatrists think about free will? Medicine, Health Care and Philosophy 12: 203212.

Morse, S.J. 2007. The non-problem of free will in forensic psychiatry and psychology. Behavioral Sciences and the Law 25: 203-220.

Nicholson, T.R.J., W. Cutter, and M. Hotopf. 2008. Assessing mental capacity: The mental capacity act. British Medical Journal 336: 322-325.

Owen, G., G. Richardson, A.S. David, G. Szmukler, P. Hayward, and M. Hotopf. 2008. Mental capacity to make decisions on treatment in people admitted to psychiatric hospitals: Cross sectional study. British Medical Journal 337: 448-451.

Paterick, T.J., G.V. Carson, M.C. Allen, and T.E. Paterick. 2008. Medical informed consent: General considerations for physicians. Mayo Clinic Proceedings 83(3): 313-319.

Paulus, M.P. 2007. Decision-making dysfunctions in psychiatryaltered homeostatic processing? Science 318: 602-606.

Raymont V, W. Bingley, A. Buchanan, A.S. David, P. Hayward, S. Wessely, and M. Hotopf. 2004. Prevalence of mental incapacity in medical inpatients and associated risk factors: Cross-sectional study. Lancet 16-22; 364(9443): 1421-1427.

Rogers, R., and K.W. Sewell. 1999. The R-CRAS and insanity evaluations: A re-examination of construct validity. Behavioral Sciences and the Law 17: 181-194.

Sevy S., K.E. Burdick, H. Visweswaraiah, S. Abdelmessih, M. Lukin, E. Yechiam, and A. Bechara. 2007. Iowa gambling task in schizophrenia: A review and new data in patients with schizophrenia and co-occurring cannabis use disorders. Schizophrenia Research 92(1-3): 74-84.

Simon, R.I. 2005. Ethics and forensic psychiatry. In Kaplan and Sadock's comprehensive textbook of psychiatry, 8th ed, ed. B.J. Sadock, and V.A. Sadock. Philadelphia: Lippincott Williams and Wilkins.

Spike, J.P. 2008. Patients' competence to consent to treatment (comment on Appelbaum 2007). New England Journal of Medicine 358(6): 644.

Stone, A.R. 2008. The ethical boundaries of forensic psychiatry: A view from the ivory tower. The Journal of the American Academy of Psychiatry and the Law 36(2): 167-174.

Thornton, T. 2007. Essential philosophy of psychiatry. New York: Oxford University Press.

Van der Scheer, L., and G. Widdershoven. 2004. Integrated empirical ethics: Loss of normativity? Medicine, Health Care and Philosophy 7: 71-79.

Van Marle, H., and P. Van der Kroft. 2007. Research issues in forensic psychiatry. Current Opinion Psychiatry 20: 511-515.

Vellinga, A. 2006. To know or not to be. Development of an instrument to assess decision-making capacity of cognitively impaired elderly patients. Delft: Nivo.

Vellinga, A., J.H. Smit, E. Van Leeuwen, W. Van Tilburg, and C. Jonker. 2004. Instruments to assess decision-making capacity: An overview. International Psychogeriatrics 16: 397-419.

Welie, S.P.K. 2008. Criteria for assessment of patient competence. A conceptual analysis from the legal, psychological and ethical perspective. Davenport, Iowa: Fidlar Doubleday.

Welie, J.V.M., and S.P.K. Welie. 2001. Patient decision making competence: Outlines of a conceptual analysis. Medicine, Health Care and Philosophy 4: 127-138.

Widdershoven, G., T. Hope, J. McMillan, and L. Van der Scheer. 2008. Empirical ethics in psychiatry. Oxford: Oxford University Press.

Zemishlany, Z., and Y. Melamed. 2006. The impossible dialogue between psychiatry and the judicial system: A language problem. Israel Journal of Psychiatry and Related Sciences 43(3): 150 158. 